\title{
TMS Finances: Looking Back at a Year of Progress
}

\author{
Stanley M. Howard
}

TMS is a member-driven professional society, which means that the Board of Directors (BOD) is composed of TMS members who set TMS policies and directions including financial matters. The Financial Planning Committee (FPC) provides the BOD with recommendations on TMS financial matters. Of course, TMS also relies on the professional staff to implement policies and to carry out the administrative activities of the society.

Financial resources for the society derive from professional meetings, subscriptions and related-knowledge products, membership dues, and other sources that cover the direct expenses for delivery of these products and services, support for member services such as students and professional development, and TMS staff support. Figure 1 shows the major components of revenues and expenses by percentage for the fiscal year 2010 .

Fiscal year 2010 (unaudited) results were very positive with revenues of $\$ 5,749,279$ and expenses of $\$ 5,136,280$, resulting in excess revue of $\$ 612,999$ or $10.66 \%$ of revenue, which is a record high. Contributing factors to this excellent result include higher-than-planned conference and event revenues, and subscription and advertising sales performing better than plan, in addition to a strategic growth in contracts.

TMS Board policy determines the use of excess revenue generated by society operations, which is divided between the TMS reserve fund and staff compensation through a bonus and incentive plan. As of April 30, 2011, the TMS reserve fund balance in investments was $\$ 2,000,272$. From 2010 results, the Board has directed over $\$ 400,000$ to be added to the TMS re-

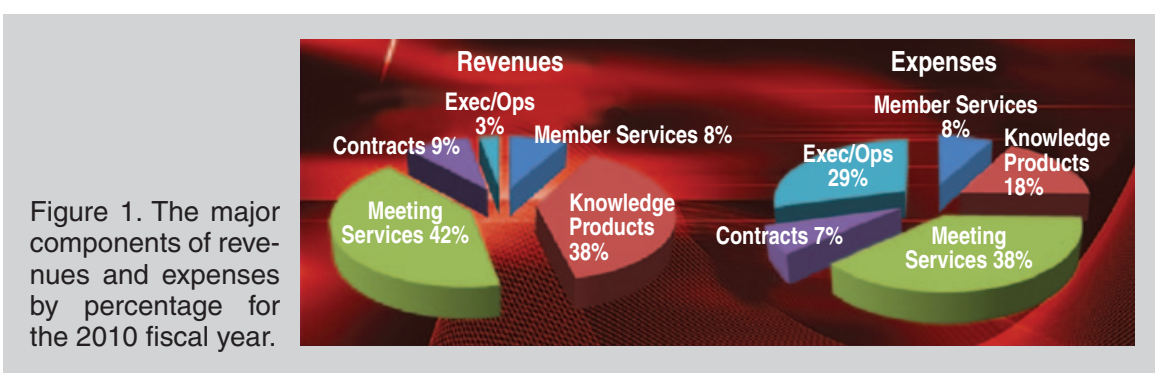

serve fund.

The TMS reserve fund is used for two primary purposes:

- Provide resources in the event of severe economic conditions. For this reason, the Board has set a minimum level of $25 \%$ of annual operating revenue to be maintained in the reserve fund.

- To support strategic TMS initiatives including the development of new products and services for TMS members.

Currently funded initiatives include resources to support the strategic technical growth initiatives in areas such as energy and computational materials science and engineering as well as the volunteerism initiative intended to strengthen TMS's position as a volunteer-centric professional society. As initiatives succeed and become integrated into recurring TMS operations, the derived revenues and associated expenses transition into the operating budget. The BOD has devoted considerable effort establishing efficient and clear procedures for the use of reserve funds to promote initiatives valued by TMS members. Growth of the reserve fund to enable expansion of member services and to provide increased financial stability for the society is an important financial priority.

In addition to the reserve fund, the society also maintains a TMS Foundation fund, which on April 30, 2011 had a balance of $\$ 2,055,902$. The FPC sets policy on the amounts drawn from the Foundation account, typically between $5 \%$ and $7 \%$ of the fund balance, to fund ongoing activities such as awards, scholarships, and the Young Leaders Program. The total expense for these programs in 2010 was $\$ 131,895$.

The TMS Foundation Board, which is comprised of members of the TMS Executive Committee, is working to grow the Foundation fund so TMS may meet rapidly expanding needs and opportunities. Of particular interest is additional funding for scholarships, volunteer recognition, and activities benefiting students that could build on the Materials and Society theme.

In conclusion, the TMS BOD faithfully exercises its fiduciary responsibilities through diligent and careful monitoring and advice from the FPC, investment advisors, and the TMS staff. Additional information regarding Society activities and financials is included in the 2010 Annual Report, which may be downloaded at www.tms.org/Society. Additional information regarding the TMS Foundation, including how to make a tax-deductible contribution, is at www.tms.org/Foundation/tfhome.aspx.

Stanley M. Howard, Professor, South Dakota School of Mines \& Technology, is the TMS Financial Planning Officer. 